\title{
OUTSIDERS NA POLÍTICA E OUTLIERS NAS REDES: UMA ANÁLISE DO USO DAS MÍDIAS SOCIAIS PELOS DEPUTADOS ESTADUAIS DO SUL E DO NORDESTE
}

Rafael Linhares e Padilha ${ }^{1}$

\begin{abstract}
Resumo
O presente trabalho busca realizar uma análise comparada da utilização das principais mídias sociais (Facebook, Instagram, Twitter e Youtube) pelos Deputados Estaduais da legislatura de 2019-2023 correspondentes a região Sul e ao Nordeste, com o intuito de avaliar quais atores da atual elite política enquadram-se como outsiders na política e outliers nas redes. Para a realização da pesquisa, foram coletados dados quantitativos das respectivas mídias digitais de todos os atuais deputados de ambas as regiões citadas. Nossa hipótese inicial é a de que: partindo de uma lacuna da literatura, dentre os parlamentares com maior quantidade de seguidores em suas mídias sociais, os outliers, deve ser possível notar níveis positivos de associação com os deputados classificados como outsiders. Os resultados obtidos negam nossa hipótese inicial visto que os resultados dos testes retornaram valores que apresentam baixa significância estatística. Assim, os achados do presente trabalho nos demonstram um amplo tema a ser explorado pela literatura científica da Ciência Política visto que a área carece de trabalhos cruzando o conceito de outsider com os padrões uso das tecnologias digitais. Ainda, para uma análise mais completa, é necessário um estudo envolvendo todas as regiões do país para assim realizar um mapeamento mais detalhado sobre os conceitos desenvolvidos.
\end{abstract}

Palavras-Chave: outsiders; outliers; redes sociais; Deputados Estaduais.

\section{INTRODUÇÃO}

Existe alguma relação entre os parlamentares eleitos sem experiência prévia na política e o sucesso no uso de mídias sociais durante seus mandatos? O objetivo deste texto é realizar uma investigação sobre a intensidade de uso das tecnologias digitais pelos Deputados Estaduais brasileiros correspondentes à legislatura de 2019-2023 dos estados do Sul e do Nordeste, examinando a quantidade de seguidores nas redes sociais mais utilizadas (Facebook, Instagram, Twitter e Youtube) pelos parlamentares e assim identificar quais deputados enquadram-se na categoria de outliers nas redes, relacionando esses dados com o conceito de outsider trabalhado de diferentes formas ao longo do tempo pelas Ciências Sociais. Essa relação dos conceitos apresentados procura ser demonstrada de um modo que seja possível elucidar a existência, ou não, da relação entre ser outlier nas redes e pertencer a categoria de outsider na política.

Embora a literatura sobre outsiders seja tema amplamente debatido nas Ciências Sociais, seja no âmbito do comportamento individual, ou na análise das relações de poder na sociedade, na área

\footnotetext{
1 Graduando em Ciências Sociais com ênfase em Ciência Política pela Universidade Federal do Paraná, rafaellinhares3030@gmail.com, https://orcid.org/0000-0003-3415-844
} 
da Ciência Política, esses estudos tendem a observar apenas as características das elites políticas e relaciona-las com o conceito de outsider. Assim, estudos que confrontam a conceituação de outsider com o uso das tecnologias digitais ainda são incipientes na área, o que demonstra um amplo campo temático a ser explorado pelos cientistas políticos. Em contrapartida disso, os trabalhos que envolvem internet e política constituem um amplo campo de estudo multidisciplinar, sendo tema de diversos artigos já produzidos no Brasil, (SAMPAIO, BRAGATTO \& NICOLAS, 2016) e assim servem como uma das bases referenciais para o desenvolvimento do presente trabalho.

Inicialmente, a delimitação da investigação entre as regiões do Sul e do Nordeste brasileiro vem da literatura (BRAGA, 2013), no qual a escolha dessas regiões parte das diferenças dos condicionantes socioeconômicos no uso das tecnologias digitais pelos parlamentares dessas localidades, entre outros fatores. Ainda nesse sentido, o resultado da análise de dados sobre uso de mídias sociais entre os Deputados Estaduais em trabalhos anteriores (CRUZ, 2011) mostram uma diferença significativa no uso dessas tecnologias entre ambas as regiões.

Neste trabalho, além do referencial da literatura, a base para a escolha das regiões parte também da diferença no perfil partidário dos parlamentares eleitos em 2018 para ambas as regiões. Como mostra a tabela a seguir:

TABELA 1: NÚMERO DOS PARLAMENTARES ELEITOS EM CADA REGIÃO POR PARTIDO (\%)

\begin{tabular}{|l|r|r|}
\hline \multicolumn{1}{|c|}{ PARTIDO } & \multicolumn{1}{|c|}{ SUL } & NORDESTE \\
\hline AVANTE & 0 & 2,3 \\
\hline DEM & 2,7 & 5,2 \\
\hline MDB & 12,7 & 7,5 \\
\hline NOVO & 1,3 & 0,0 \\
\hline PATRI & 0 & 1,7 \\
\hline PC do B & 0 & 4,3 \\
\hline PDT & 5,3 & 8,0 \\
\hline PMN & 0,7 & 0,6 \\
\hline PHS & 0 & 0,9 \\
\hline PODE & 1,3 & 2,3 \\
\hline PP & 8,0 & 10,1 \\
\hline PPL & 0,7 & 0,3 \\
\hline PPS & 2,7 & 2,0 \\
\hline PR & 4,7 & 4,0 \\
\hline PRB & 2,7 & 2,0 \\
\hline PROS & 1,3 & 1,4 \\
\hline PRP & 0 & 0,3 \\
\hline PRTB & 0,7 & 2,6 \\
\hline
\end{tabular}




\begin{tabular}{|c|c|c|}
\hline PSB & 7,3 & 8,0 \\
\hline PSC & 3,3 & 3,7 \\
\hline PSD & 8,0 & 6,9 \\
\hline PSDB & 6,0 & 5,5 \\
\hline PSL & 12,0 & 2,6 \\
\hline PSOL & 0,7 & 1,1 \\
\hline PT & 10,7 & 7,8 \\
\hline PTB & 4,0 & 2,6 \\
\hline PTC & 0 & 0,9 \\
\hline PV & 2,0 & 1,4 \\
\hline REDE & 0 & 0,9 \\
\hline REPUBLICANOS & 0 & 0,3 \\
\hline SOLIDARIEDADE & 0,7 & 2,6 \\
\hline TOTAL & 100 & 100 \\
\hline
\end{tabular}

FONTE: GEIST-UFPR (2020)

Assim, os dados nos demonstram que na região Sul, os partidos que mais detém parlamentares são, MDB, PSL e PT cada um com um percentual de 12,7\%, 12\% e 10.7\%, respectivamente. Seguidos por PP (8\%), PSD (8\%), PSB (7.3\%), PSDB (6\%), PDT (5.3\%), PR (4.7\%), PTB (4\%), DEM (2.7\%), PPS (2.7\%), PRB (2.7\%), PSC (3.3\%) e PV, NOVO, PMN, PODE, PPL, PROS, PRTB, PSOL, SOLIDARIEDADE com $2 \%$ ou menos de parlamentares cada. A representação gráfica abaixo demonstra a porcentagem da bancada dos partidos na região Sul.

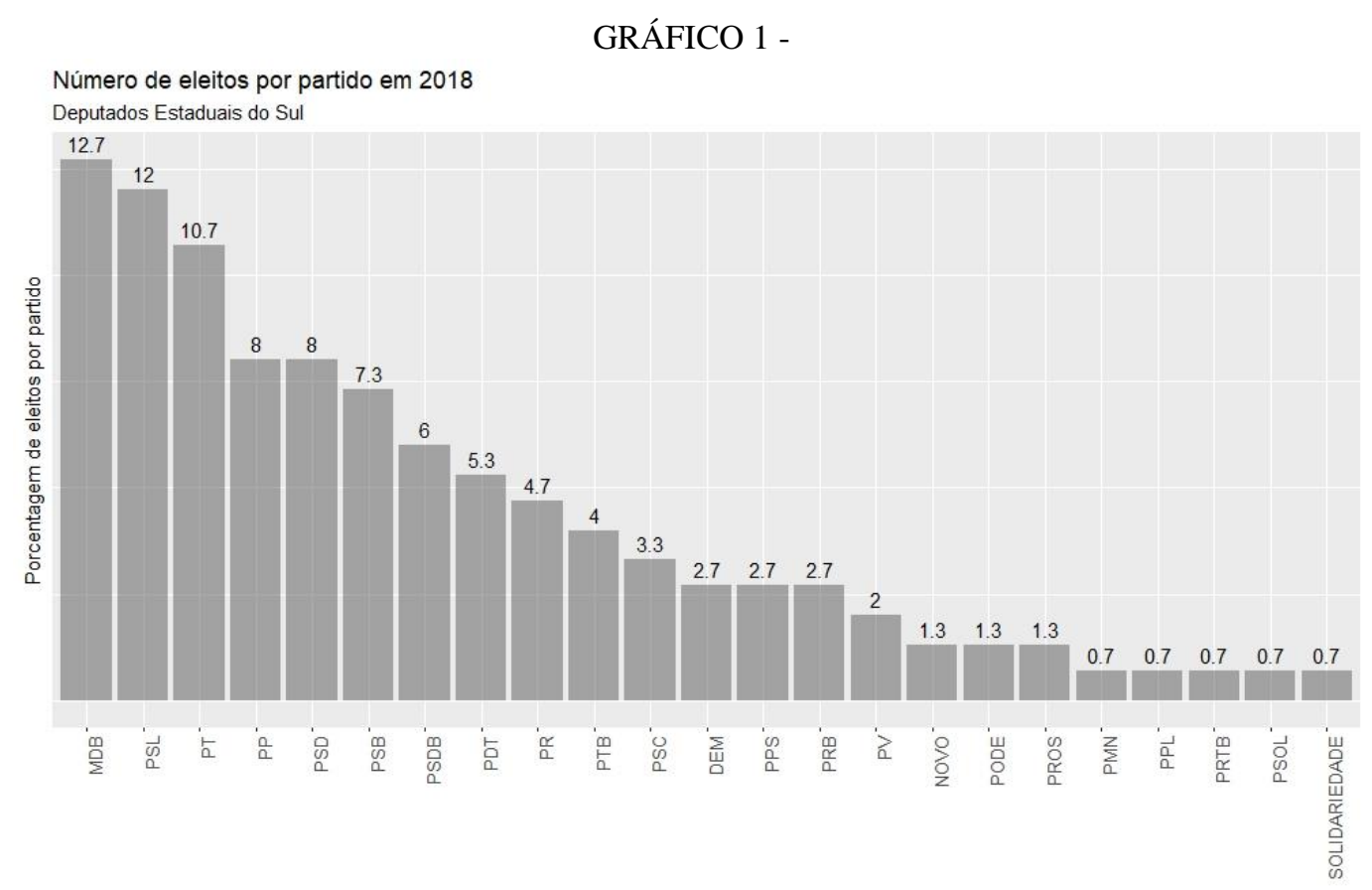

FONTE: GEIST-UFPR (2020) 
O percentual de parlamentares eleitos por partido no Nordeste mostra que o partido que detém maior percentual é o PP, com 10.1\% de cadeiras, seguido por PDT (8\%), PSB (8\%), PT (7.8\%), MDB (7.5\%), PSD (6.9\%), PSDB (5.5\%), DEM (5.2\%), PC do B (4.3\%), PR (4\%), PSC (3.7\%), PRTB (2.6\%), PSL (2.6\%), PTB (2.6\%), SOLIDARIEDADE (2.6\%), AVANTE (2.3\%), PODE (2.3\%), PPS (2\%), PRB (2\%), PATRIOTA (1.7\%), PROS(1.4\%), PV(1.4\%), PSOL (1.1\%) e PHS, PTC, REDE, PMN, PPL e PRP e REPUBLICANOS com menos de 1\% cada. Como mostra o gráfico abaixo.

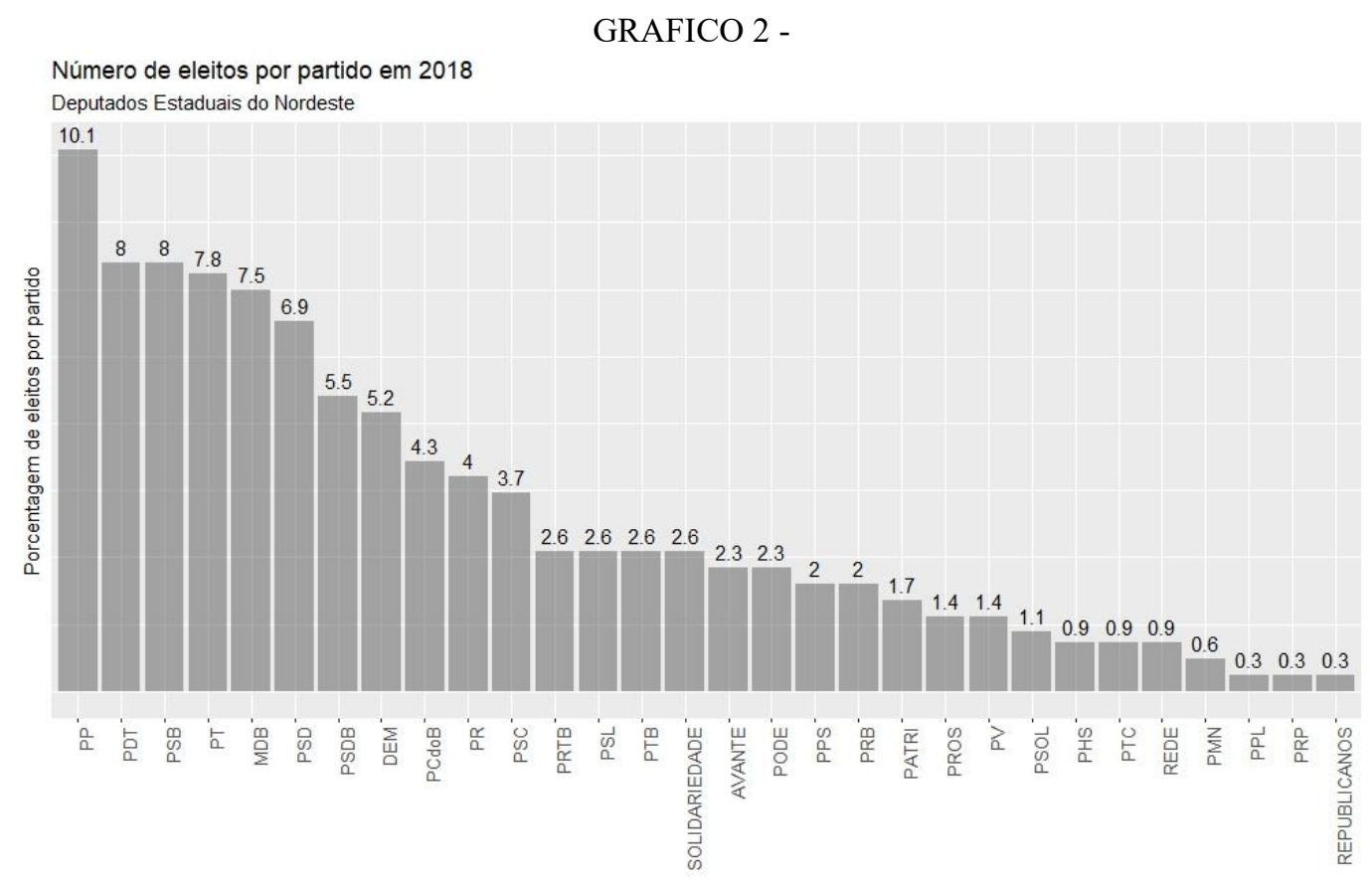

FONTE: GEIST-UFPR (2020)

Um dado interessante, que embasa a delimitação geográfica da análise proposta, é que os dois partidos que detém maior número de parlamentares em uma região não são os mesmos que detém na outra. No Sul, os partidos que constituem maior número de Deputados Estaduais são MDB, com 19 parlamentares que correspondem a $12.7 \%$ das cadeiras e o PSL que possui com 18 deputados, correspondendo a 12\%. Em comparação com o Nordeste, esses dois partidos detém menos cadeiras, proporcionalmente, não estando entre os dois partidos com maiores bancadas na região. No Nordeste, o MDB possui 26 parlamentares eleitos correspondendo a 7.5\% das cadeiras e o PSL possui apenas 9 parlamentares, correspondendo a $2.6 \%$ das cadeiras. O mesmo ocorre com os dois maiores partidos do Nordeste em comparação com o Sul, o PP possui 33 parlamentares no Nordeste correspondendo a $10.1 \%$ dos parlamentares totais. Seguido pelo PDT e PSB, com 28 parlamentares e $8 \%$ da bancada 
cada. Em comparação com o Sul, PP e PSB possuem 8\% e 7.3\% da bancada e 12 e 11 parlamentares respectivamente.

Ainda, é possível notar a existência de partidos que elegeram parlamentares em apenas uma região. É o caso dos partidos PC do B, AVANTE, PATRIOTA, PTC e REDE, em que no Sul não conseguiram eleger nenhum parlamentar e no Nordeste representam 4.3\%, 2.3\%, 1.7\%, 0.9\% e 0.9\% do total de Deputados eleitos respectivamente. No Nordeste, o único partido que não elegeu parlamentares foi o NOVO, enquanto no Sul o partido possui $1.3 \%$ da bancada.

Uma posição interessante a se comparar entre as regiões é dos partidos PT e PDT, onde o PT possui maior bancada percentual no Sul, estando entre os três maiores partidos da região e o PDT é o segundo, empatado com o PSB, com maior bancada em número de Deputados Estaduais no Nordeste, enquanto no Sul corresponde a oitava posição em tamanho de bancada. Olhando para o PT, o partido detém 16 parlamentares correspondentes a $10.7 \%$ da bancada, sendo o terceiro partido que mais possui Deputados Estaduais na região Sul. Já no Nordeste, o partido está na quarta posição no número de parlamentares, possuindo 27 deputados e correspondendo a 7.8\% da bancada. Já o PDT, como mencionado anteriormente, no Sul possui 8 parlamentares correspondendo a $5.3 \%$ da bancada, enquanto no Nordeste o partido detém 27 deputados correspondendo a $8 \%$ da bancada.

Assim, a principal hipótese que buscamos discutir ao decorrer do texto é: partindo de uma lacuna da literatura, dentre os parlamentares com maior quantidade de seguidores em suas mídias sociais, os outliers, deve ser possível notar níveis positivos de associação com os deputados classificados como outsiders. Além disso, queremos avaliar como se distribui, em termos percentuais, a presença digital dos Deputados Estaduais no Sul e no Nordeste.

As informações utilizadas para realização do presente artigo fazem parte das bases de dados do Grupo de Pesquisa Atores, Instituições Políticas e Tecnologias Digitais (GEIST - UFPR), que dedica-se à análise do uso dos diferentes meios digitais pela elite política. Dessa forma, este trabalho está no âmbito de interesses temáticos do grupo de pesquisa e procura contribuir para expansão das análises de outsiders e outliers com o uso das redes sociais aplicado ao campo da Ciência Política.

\section{REFERENCIAL TEÓRICO}

O desenvolvimento do conceito de outsider consolida-se a partir do século XX com a publicação denominada “Os Estabelecidos e os Outsiders: Sociologia das relações de poder a partir 
de uma pequena comunidade", realizada no ano de 1950 e publicado em 1965 pelo sociólogo alemão Norbert Elias. Esse livro trabalha com a análise de uma pequena comunidade inglesa, com o nome fictício de Winston Parva, esta comunidade poderia ser resumida no grupo de indivíduos moradores da mesma, os estabelecidos, e os forasteiros, tradução essa que deu origem ao nome do conceito trabalhado, que vinham de outras localidades com diversas finalidades e comportamentos distintos do grupo que residia ali anteriormente, esses indivíduos "novos" na comunidade são denominados de outsiders. A pesquisa de Elias traz ainda relações importantes entre grupos de estabelecidos e outsiders que são de grande importância para o desenvolvimento dessa temática.

Como em Sociologia, a principal diferença entre estabelecidos e outsiders são os comportamentos desses dois grupos, onde é uma característica dos outsiders possuir comportamentos desviantes a um padrão de regras pré-estabelecido (BECKER, 1963), utilizar essas categorias analíticas no sentido sociológico clássico ao qual são empregadas não ajudam na definição do conceito para analisar o mundo político, mas servem como base teórica para o desenvolvimento do mesmo.

Como dito anteriormente, pesquisas que trabalham com a temática de análise de indivíduos que apresentam comportamentos destoantes na sociedade, os outsiders, já são temas recorrentes nas Ciências Sociais, principalmente na Sociologia que utiliza o conceito para análise comportamental e cultural. Já a Ciência Política trabalha com o conceito outsider não com foco no comportamento do ator político, mas sim olhando para qual posição ele ocupou anteriormente ou após tomar posse de seu mandato e é isso que dificulta a definição do outsider no campo da política. Outro impasse encontrado para definir o ator político outsider na Ciência Política referente à literatura é relacionado com o cargo escolhido para análise de outsiders, grande parte dos politólogos opta por utilizar o conceito de outsider para analisar políticos advindos dos cargos do poder executivo como presidentes, ministros e secretários de governo (BARR, 2009; CARRERAS, 2014; CORRALES, 2008.), faltando exemplos na literatura para a análise de atores outsiders em cargos do poder legislativo.

Ainda assim existem trabalhos que analisam o legislador, onde a classificação do político outsider também perpassa por exame bibliográfico com a finalidade de analisar o cargo ocupado anteriormente e os anos de experiência prévia na política (MARRENCO, 1997), e assim, então, definir quem são os políticos outsiders.

Portanto, pela literatura, é possível mapear autores que trabalham a análise deste agente vinculada com sua experiência política em cargos eletivos e/ou de administração pública (CORRALES, 2008) e sua visibilidade e a posição em que ocupa perante os partidos tradicionais (BARR, 2009). Esse é um problema analítico encontrado e que cabe ao pesquisador escolher qual das 
definições mais se enquadra ao seu tema de pesquisa. Então, é possível traçar duas linhas gerais para analisar os outsiders na perspectiva da Ciência Política: I) outsiders como candidatos sem experiência prévia na política; II) outsiders como candidatos fora do establishment político. O primeiro referencial analítico parte da experiência eleitoral de determinado ator político, neste modelo são designados outsider os políticos que não tiveram experiência em ocupação de cargos eletivos anteriormente (CARRERAS, 2016). A segunda forma de conceituação do ator político outsider é do candidato que não faz parte de grandes partidos políticos tradicionais e competitivos (BARR, 2019). Ambas as linhas de definição trazem consigo problemas (CORRALES, 2008) pois englobam características diferentes, mais ou menos restritivas, dos atores políticos e podem causar dualidade no conceito.

Para a presente investigação, tomamos como referencial a primeira definição de ator político outsider apresentada acima, considerando outsider apenas os políticos que não tiveram experiência política prévia em cargos eletivos (CARRERAS, 2016). Essa escolha é de cunho metodológico, como trabalhamos com um universo muito grande de parlamentares e com políticos pertencentes aos legislativos estaduais, optar por utilizar a segunda para definir quem seriam os outsiders poderia enviesar os dados, diante disso, se escolhermos a segunda linha, uma das formas de classificação é a auto definição dada pelo próprio parlamentar(CORRALES, 2008), o que resultaria em perda de precisão conceitual e analítica.

Para caracterizar os parlamentares outliers nas redes utilizamos a conceituação estatística de valores destoantes de um padrão comum (CERVI, 2017) e assim olhamos apenas para os valores superiores. Esses, por sua vez, indicam os parlamentares que mais possuem seguidores em suas mídias sociais em ambas as regiões analisadas. A fórmula de análise e o ferramental utilizado será elucidado adiante.

\section{METODOLOGIA}

A coleta das informações para a formação do banco de dados ocorreu ao longo do ano de 2019 e contou com a contribuição dos pesquisadores do Grupo de Pesquisa Atores, Instituições Políticas e Tecnologias Digitais (GEIST - UFPR). Foram coletados dados do Facebook, Instagram, Youtube e Twitter relacionados a curtidas, seguidores, posts e inscrições de 1066 Deputados Estaduais, entre os quais, após o recorte geográfico, corresponderam a 149 parlamentares eleitos na região Sul e 347 no Nordeste, totalizando 496 Deputados Estaduais analisados em ambas as regiões. 
A abordagem adotada é a de análise quantitativa com o objetivo de identificar os outliers superiores na distribuição dados, em ambas as regiões, seguido pela atribuição da variável qualitativa outsider nos valores correspondentes aos parlamentares encontrados nas quatro redes sociais analisadas. Então, definimos outlier como a concepção estatística de elementos destoantes de um padrão conhecido, sendo tratado como observações específicas (CERVI, 2017) e realizamos a filtragem primeiramente pela variável referente a possuir ou não perfil na rede social, após essa primeira filtragem, aplicamos a seguinte fórmula, via software R, para identificar os valores que são correspondentes aos outliers superiores do nosso banco de dados: Q3 + (3 x L). O resultado retornou os limites superiores correspondentes aos valores extremos no Facebook, Instagram, Twitter e Youtube, que indica que os parlamentares que possuírem seguidores acima desse limite são os outliers da distribuição e a parir disso juntamos esses valores em banco de dados separados para a classificação referente ao parlamentar ser ou não outsider na política.

Diante disso, para o questionamento da nossa hipótese, utilizamos informações obtidas a partir do uso das medidas de posição e formação de boxplot's para melhor visualização dos dados. Então, foi utilizado o teste $t$ de student com o agregado dos deputados (496) e segmentando por rede social com a finalidade de comparar as médias entre as duas regiões e demonstrar se os padrões de uso das redes entre os deputados em ambas as regiões são próximos ou distantes. Os resultados serão discutidos ao decorrer do texto e mostrarão que a existência ou não da diferença de médias entre as regiões depende da rede social.

Após a identificação dos outliers com o auxílio do software R, esses parlamentares foram separados em banco de dados próprios para serem analisados de maneira independente dos demais e então utilizamos o teste qui-quadrado para avaliar o quão forte é a relação entre ser outlier nas redes e outsider na política, assim como essa relação entre as regiões. Em suma, o que o teste nos mostrou é que não existem entre esses dois grupos diferenças estatisticamente significativas, negando nossa hipótese.

\section{FREQUÊNCIA DE USO ENTRE PARLAMENTARES DA REGIÃO SUL E NORDESTE}

Com o objetivo de apresentar uma base sobre o uso das redes sociais pelos parlamentares das regiões, iremos analisar a frequência de uso das redes sociais de 496 Deputados Estaduais. Com o 
propósito de comparar com a frequência de uso das redes pelos parlamentares destas regiões. $\mathrm{O}$ resultado é apresentado abaixo:

TABELA 2: FREQUÊNCIA DE USO DE FERRAMENTAS DIGITAIS

\begin{tabular}{l|cc}
$\begin{array}{l}\text { RECURSOS DE E- } \\
\text { CAMPANHA }\end{array}$ & SUL & NORDESTE \\
\hline FACEBOOK & $98 \%$ & $94.8 \%$ \\
INSTAGRAM & $93.3 \%$ & $89.9 \%$ \\
TWITTER & $82.7 \%$ & $62.6 \%$ \\
YOUTUBE & $78.7 \%$ & $40.5 \%$ \\
\hline$\quad$ MÉDIAS $\quad 88 \%$ & $72 \%$ \\
$\quad$ TOTAL DE & 149 & 347 \\
PARLAMENTARES & &
\end{tabular}

FONTE: GEIST-UFPR (2020)

A tabela acima mostra dados relativos à representação dos parlamentares nas redes sociais. Olhando a primeira parte da tabela, referente às redes sociais, podemos notar que a frequência de uso das mesmas é maior em todas as redes se comparadas as duas regiões. No Sul, 98\% de parlamentares usam o Facebook para se comunicar, enquanto no Nordeste esse número é de $94.8 \%$, sendo o número apresentado próximo entre as duas regiões. A frequência de uso do Instagram pelos Deputados Estaduais do Sul corresponde a $93.3 \%$ e no Nordeste a $89.9 \%$ e, assim como no caso do Facebook, essa é uma rede bem aceita pelos parlamentares, visto que em ambos os casos essa redes sociais tiveram praticamente $90 \%$ de uso ou mais pelos parlamentares de ambas as regiões. Observando os dados sobre o uso do Twitter, conseguimos notar a primeira grande diferença nos números: enquanto no Sul $82.7 \%$ dos Deputados Estaduais são adeptos dessa rede, apenas 62.6\% a utilizam no Nordeste. Essa diferença também está presente no Youtube, enquanto no Sul 78.7\% dos parlamentares possuem canal nesta mídia, apenas $40.5 \%$ estão presentes no Nordeste. Agora, olhando para as médias gerais do uso das redes sociais pelos parlamentares, conseguimos notar que, no geral, o Sul possui uma média geral de uso de $88 \%$ sendo diferente da outra região analisada, onde sua média corresponde a $72 \%$.

\section{OUTLIERS}

Como já concluído por Braga e Carlomagno (2018), é crescente o uso de ferramentas digitais e mídias sociais nos pleitos atuais, fazendo com que seja possível a inserção de candidatos que antes 
não eram visíveis no jogo político. Com isso, a utilização de recursos de e-campanhas tornou-se ferramenta essencial para candidatos sem capacidade de mobilização anterior, promovendo o acesso de diversos atores às disputas eleitorais e, consequentemente, aumentando a competitividade das eleições. Ainda que a mudança na formação da imagem e a difusão do uso das redes pelos atores políticos seja amplamente discutia na literatura, a análise desses atores que usam as redes de maneira eficiente, seja os que não advém de cargos eletivos anteriores ou seja os que implementaram esse uso enquanto mandatários, ainda é incipiente na literatura e merece atenção dos pesquisadores.

É nesse sentido que o presente trabalho caminha, olhando para os parlamentares que mais possuem seguidores em suas redes sociais e, por consequência disso, tem uma maior profissionalização de seu uso. Assim, buscamos relacionar esse uso mais profissionalizado com o conceito teórico de outsider trabalhado na Ciência Política.

Então, para nossa análise em âmbito mais geral e com a finalidade de identificar quem são os outliers de cada região e em cada rede, partiremos do nosso banco de dados completos com todos os Deputados Estaduais do Sul e do Nordeste. Assim, contamos com um número de 496 deputados eleitos nessas duas regiões no pleito do ano de 2018 e dados sobre sua representação no Facebook, Instagram, Twitter e Youtube. Primeiro filtramos os parlamentares que possuem ou não perfil em cada rede, como mostrado na tabela 1 apresentada anteriormente, e assim aplicamos a fórmula para identificar os outliers superiores, o resultado pode ser observado na tabela a seguir:

TABELA 3: ESTATÍSTICAS REFERENTES AO NÚMERO DE SEGUIDORES NOS PERFIS DOS PARLAMENTARES (REGIÕES AGREGADAS)

\begin{tabular}{|c|c|c|c|c|c|c|c|}
\hline $\begin{array}{l}\text { RECURSOS E- } \\
\text { CAMPANHA }\end{array}$ & $\begin{array}{c}\text { VALOR } \\
\text { MÍNIM } \\
\text { O }\end{array}$ & $\begin{array}{c}1^{\circ} \mathrm{QUARTI} \\
\mathrm{L}\end{array}$ & $\begin{array}{c}\text { MEDIAN } \\
\text { A }\end{array}$ & $\begin{array}{c}3^{\circ} \text { QUARTI } \\
\text { L }\end{array}$ & $\begin{array}{l}\text { MÉDI } \\
\text { A }\end{array}$ & $\begin{array}{c}\text { VALOR } \\
\text { MÁXIM } \\
\text { O }\end{array}$ & $\begin{array}{c}\text { LIMITE } \\
\text { SUPERIO } \\
\mathbf{R}\end{array}$ \\
\hline FАСЕВООК & 0 & 18.792 & 36.996 & 64.010 & 75.206 & 3.842 .730 & 135.699 \\
\hline $\begin{array}{l}\text { INSTAGRA } \\
\mathrm{M}\end{array}$ & 0 & 4.824 & 9.480 & 15.830 & 16.216 & 349.022 & 33.027 \\
\hline TWITTER & 0 & 142 & 724 & 2624 & 4826 & 409.131 & 9.926 \\
\hline YOUTUBE & 0 & 11 & 44 & 135 & 3945 & 522.000 & 496 \\
\hline
\end{tabular}

FONTE: GEIST-UFPR (2020)

Verticalmente a tabela apresenta estatísticas relacionadas aos valores mínimos e máximos da quantidade de seguidores nos perfis dos Deputados Estaduais, a média geral dessa quantidade e o limite, calculado pela fórmula demonstrada anteriormente, para um parlamentar ser considerado outlier nas redes. O valor mínimo corresponde ao menor valor encontrado entre aqueles que possuem 
perfil nas quatro redes analisadas, esse número advém de dois fatores: I) quando foi realizada a coleta de dados, os parlamentares teriam recém criado a rede social; II) os parlamentares não a utilizam constantemente, logo não criam engajamento em suas mídias.

O primeiro quartil faz referência aos $25 \%$ iniciais da distribuição, isso quer dizer que do valor mínimo até o valor correspondente ao primeiro quartil estão situadas $1 / 4$ do total de seguidores nas redes dos Deputados Estaduais. No caso do Facebook, os 25\% iniciais valor correspondem ao valor mínimo (0) até o primeiro quartil (18.792). Do primeiro quartil (18.792) até o terceiro quartil (64.010) estão situadas $50 \%$ da distribuição total. Do terceiro quartil (64.010) até o valor máximo (3.842.730) estão situados os $25 \%$ da distribuição restante e a média geral corresponde a 75.206 e o limite superior, correspondente ao valor 135.699, diz respeito ao limite da distribuição onde os valores que estiverem acima dele serão considerados outliers. Os valores encontrados nos perfis do Facebook são maiores que os das outras redes por dois fatores: I) esta mídia disponibiliza os dados de curtidores e seguidores; II) os dados apresentados para a análise do Facebook correspondem a soma de curtidores e seguidores.

Em relação ao Instagram, os primeiros $25 \%$ da distribuição vão do valor mínimo (0) até o primeiro quartil (4.824). Os valores entre o primeiro quartil até o terceiro quartil (15.830) são correspondentes aos outros $50 \%$ da distribuição. Então, do terceiro quartil até o valor máximo (349.022) estão o restante da distribuição. A média de seguidores no perfil dos Deputados Estaduais no Instagram foi de 16.216 e o limite para valores outliers correspondeu a 33.027.

No tocante ao Twitter, o intervalo entre o valor mínimo (0) e o primeiro quartil (142) indicam os $25 \%$ iniciais. Entre o primeiro quartil e o terceiro quartil (2624) estão 50\% da distribuição. A partir do terceiro quartil até o valor máximo (409.131) estão os $25 \%$ restantes. A média de seguidores das páginas dos parlamentares nessa rede social foi de 4826 e o limite superior para valores outliers foi de 9.926.

Por último o Youtube, os 25\% iniciais da distribuição correspondem ao intervalo entre o valor mínimo (0) e o primeiro quartil (11). Do primeiro quartil até o terceiro quartil (135) estão situados $50 \%$ da distribuição de inscrições no canal dos parlamentares. Os $25 \%$ seguintes são referentes ao intervalo entre o terceiro quartil e o valor máximo (522.000), a média equivale a 3945 e o limite para valores outliers é de 496. O gráfico abaixo demonstra a distribuição de seguidores nas quatro redes sociais analisadas: 


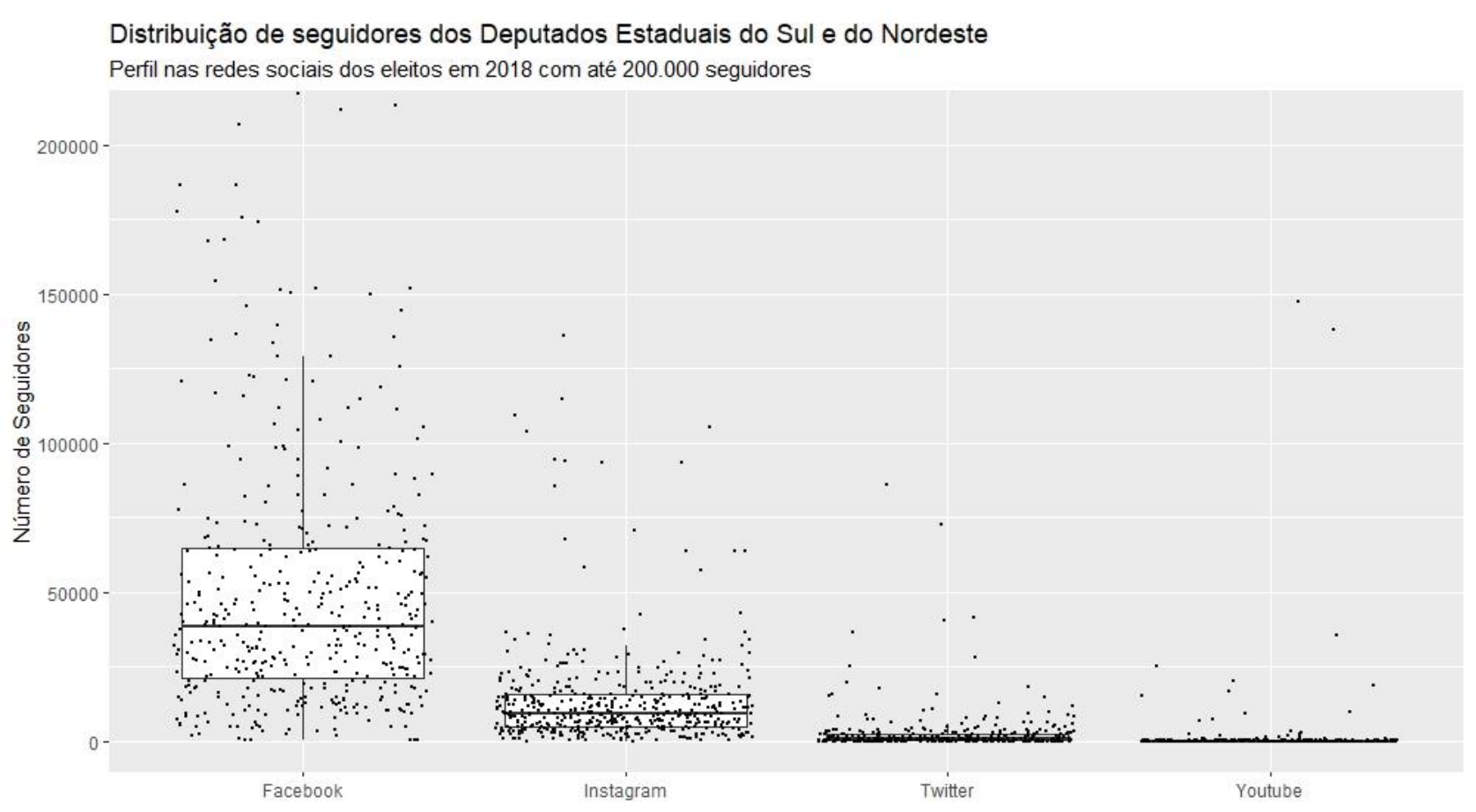

FONTE: GEIST-UFPR (2020)

Analisando a visualização gráfica é possível notar que o Facebook é a rede que mais agrega seguidores entre os Deputados Estaduais, seguido pelo Instagram, Twitter e Youtube.

Os Deputados Estaduais que possuem redes sociais com seguidores um pouco acima de 200.000 foram retirados do gráfico para melhor visualização e os outliers serão analisados adiante. Em todas as estatísticas apresentadas anteriormente, o Facebook é a que possui números maiores e também é a rede mais usada pelos parlamentares. Essa diferença nas estatísticas pode estar associada a popularização dessa rede no Brasil, fazendo com que o eleitorado esteja mais presente na mesma, assim como os Deputados. Quando analisamos as outras, podemos observar algumas diferenças nos números como, por exemplo, se olharmos para os valores máximos. Esses valores correspondem ao Deputado Estadual que mais possui seguidores na rede, nessa estatística o Facebook dos parlamentares ainda detém maior número (3.842.730), porém as outras redes ganham maior relevância sendo a seguinte o Youtube (522.000), o Twitter (409.131) e o Instagram (349.022). Uma possível explicação para esse fenômeno é a de que esses Deputados Estaduais, não apenas os que possuem a maior quantia de seguidores mas também aqueles que estão acima do limite superior, já agregavam seguidores antes de entrar na política, seja como estando em lugar de destaque em suas profissões, seja sendo "influencers" nas redes sociais. Iremos discutir este ponto mais adiante. 
Agora, separamos os parlamentares em grupos correspondentes as duas regiões, Sul e Nordeste, e aplicamos o teste $t$ de student com limite crítico de 0.05 para avaliar se entre ambos territórios existem diferenças de médias da quantidade de seguidores nas redes sociais dos parlamentares. Como podemos observar abaixo:

TABELA 4: APLICAÇÃO DO TESTE T DE STUDENT

\begin{tabular}{l|llll}
\multicolumn{1}{l}{ COEFICIENTES } & FACEBOOK & INSTAGRAM & TWITTER & YOUTUBE \\
\hline T & -2.4515 & 1.0325 & -1.4775 & 0.32848 \\
DF & 183.61 & 248.17 & 152.52 & 454.74 \\
P-VALUE & 0.01516 & 0.3029 & 0.1416 & 0.7427 \\
\hline \multicolumn{1}{c}{ MÉDIA SUL } & 124.137 & 12.740 & 6.796 & 1750 \\
MÉDIA NORDESTE & 45.641 & 15.929 & 1930 & 2412
\end{tabular}

FONTE: GEIST-UFPR (2020)

A parte superior da tabela apresenta o resultado dos coeficientes por rede social e a parte inferior as médias das regiões analisadas. Com exceção do Facebook, todas as redes apresentaram um $p$-value maior que o limite crítico aceitável para o teste t (0.05), ou seja, no Instagram, Twitter e Youtube não existem diferenças estatisticamente significativas entre as médias da quantidade de seguidores por região. O Facebook vai no sentido oposto do que foi observado nas outras três redes sociais, sendo seu p-value estatisticamente significativo (0.015) e obtendo uma diferença considerável positiva para a região Sul.

Para completar a análise dos outliers, precisamos separar esses Deputados do restante da distribuição e agregar seus dados separadamente por região. Para isso, após as análises realizadas anteriormente, filtramos novamente os que possuem rede social e separamos os parlamentares acima do limite superior, assim é possível analisarmos os outliers separadamente por região. O resultado pode ser visto na tabela abaixo:

TABELA 5: OUTLIERS NAS REDES SOCIAIS POR REGIÃO

\begin{tabular}{l|cc}
\multicolumn{1}{c}{$\begin{array}{c}\text { RECURSOS E- } \\
\text { CAMPANHA }\end{array}$} & SUL & NORDESTE \\
\hline FACEBOOK & $19(59.4 \%)$ & $13(40.6 \%)$ \\
INSTAGRAM & $9(29 \%)$ & $22(71 \%)$ \\
TWITTER & $14(41.2 \%)$ & $20(58.8 \%)$ \\
YOUTUBE & $22(52.4 \%)$ & $20(47.6 \%)$ \\
\hline
\end{tabular}

FONTE: GEIST-UFPR (2020) 
Então, podemos observar na vertical, a quantidade de parlamentares numérica e em porcentagem de outliers nas redes. Ainda, esses dados nos mostram todos os parlamentares que possuem seguidores acima do limite superior mencionado anteriormente e são, dentre o total de 496, os que mais agregam seguidores em suas redes sociais.

Inicialmente, em ambos os estados foram observados 32 parlamentares outliers no Facebook, sendo 19 (59.4\%) na região Sul e 13 (40.6\%) no Nordeste. Dentre os 31 Deputados outliers do Instagram, apenas 9 (29\%) pertencem a região Sul e $22(71 \%)$ ao Nordeste brasileiro, sendo a rede social que mais apresenta diferenças na quantidade de parlamentares outliers nas duas regiões. Assim como no Instagram, a maioria dos parlamentares outliers do Twitter estão nos estados do Nordeste, número que corresponde à 20 (58.8\%) Deputados Estaduais outliers, enquanto a quantidade de outliers no Sul é de 14 (41.2\%) do total de 34 Deputados outliers. O Youtube é a rede social que mais agrega Deputados Estaduais considerados outliers, contendo um número total de 42 parlamentares e também é a mídia social onde ambas as regiões mais se igualam em porcentagem.

\section{OUTSIDERS}

Para iniciar os testes a respeito do uso das redes sociais pelos Deputados Estaduais outsiders, iremos utilizar os dados correspondentes aos parlamentares outliers e, a parir daí, categorizando como outsiders ou não. Após essa categorização, procuramos rodar os testes estatísticos para elucidação da indagação do presente estudo. Os dados que foram utilizados sobre as carreiras dos Deputados Estaduais foram obtidos a partir da análise biográfica de cada um dos eleitos nas Câmaras Estaduais que, na maioria das vezes, forneciam essa informação. Quando ela não era oferecida, a informação sobre a carreira dos parlamentares, procurávamos no web site do parlamentar. Dessa forma, a conceituação de outsider que nós entendemos como mais adequada para nosso objeto de estudo opera nas características mencionadas anteriormente e pode ser resumida em: parlamentares sem experiência prévia em cargos eletivos.

Então, aplicamos o teste de qui-quadrado de Pearson para avaliar a existência de diferenças estatisticamente significativas entre o parlamentar ser outlier nas redes e outsider na política. $\mathrm{O}$ resultado pode ser analisado com a tabela a seguir: 
TABELA 6: TESTE DE QUI-QUADRADO PARA PARLAMENTARES OUTLIERS

\begin{tabular}{l|llll}
$\begin{array}{l}\text { TESTE DE } \\
\text { QUI- } \\
\text { QUADRADO }\end{array}$ & FACEBOOK & INSTAGRAM & TWITTER & YOUTUBE \\
\hline X-SQUARED & 1.125 & 0.032258 & 19.882 & \\
DF & 1 & 1 & 1 & 3.4286 \\
P-VALUE & 0.2888 & 0.8575 & 0.000008236 & 0.06408 \\
\hline OUTSIDER & & & & \\
$\quad$ SIM & 13 & 16 & 4 & 15 \\
$\quad$ NÃO & 19 & 15 & 30 & 27 \\
TOTAL & 32 & 31 & 34 & 42
\end{tabular}

FONTE: GEIST-UFPR (2020)

Na parte superior da tabela temos os coeficientes do teste de qui-quadrado de Pearson e na parte inferior os dados sobre frequência de parlamentares outsiders entre os Deputados Estaduais outliers nas redes. O primeiro ponto a se analisar é o $p$-value que representa a significância estatística desses dados, isto é, o quanto ser outlier está condicionado ao fator outsider. Para que se possa afirmar que, entre os outliers, os outsiders agregam mais seguidores que os políticos tradicionais é necessário que primeiro o p-value seja igual ou menor do que 0.05. Além disso, é necessário observar a frequência de Deputados Estaduais outsiders para avaliar se ela é mais positiva ou negativa.

Dito isso, o $p$-value para o Facebook, Instagram e Youtube retornaram um valor superior a 0.05, sendo $0.2888,0.8575$ e 0.06408 respectivamente e mostra que não existem diferenças estatisticamente significativas entre ser outlier nas redes e ser outsider na política para essas redes sociais. Quanto à frequência, entre os outliers no Facebook existem 13 parlamentares outsiders e 19 políticos tradicionais, totalizando 32 parlamentares. No Instagram, essa frequência de outsiders entre os outliers é de 16 e o número de políticos tradicionais entre os outliers é de 14, sendo 31 Deputados Estaduais no total. Em relação ao Youtube, a frequência de parlamentares outsiders dentre os outliers é de 15 e a de políticos tradicionais é de 27 de um total de 42 parlamentares.

Olhando agora para a rede social onde o $p$-value foi menor que 0.05 , ou seja, observou-se uma relação estatisticamente significativa entre ser outlier nas redes e outsider na política. No Twitter, o resultado do coeficiente $p$-value do teste de qui-quadrado para essa rede social é de 0.00 , o que nos indica uma forte relação entre essas duas variáveis. A frequência de outsiders entre os outliers nessa rede é apenas de 4, enquanto a de políticos tradicionais é de 30 em um total de 34 Deputados Estaduais analisados. 


\section{CONSIDERAÇÕES FINAIS}

Buscamos com o presente artigo realizar uma abordagem sobre o uso das redes sociais pelos Deputados Estaduais brasileiros, com o recorte correspondente as regiões Sul e Nordeste. Procuramos apresentar a análise a partir de dois pontos: o uso efetivo das redes sociais pelos parlamentares fazendo com que conseguissem agregar uma considerável quantia de seguidores, o que os caracteriza como outliers nas redes e, a partir daí, a aplicação da variável outsider.

Após utilizarmos a fórmula para identificação dos outliers nas mídias sociais e a manipulação do banco de dados, percebemos que um parlamentar poderia ser outlier em apenas uma rede social assim como ser categorizado nas quatro redes estudadas, fato esse nos fez segmentar a análise por rede social.

Assim, abordamos brevemente a utilização do conceito outsider pelos clássicos das Ciências Sociais que trabalham com o tema tendo por objetivo embasar o conceito teórico da maneira mais sólida possível, assim trazendo para o presente estudo os debates teóricos sobre atores outsiders na Ciência Política contemporânea. Dessa forma, notou-se que o conceito desenvolvido ainda é passível de debates pelos politólogos.

Partindo dos estudos de Braga (2013), definimos o recorte geográfico tendo como base a diferença nas médias de uso entre os parlamentares do Sul e do Nordeste no pleito de 2018 e avaliamos a utilização das principais redes pelos Deputados Estaduais de cada região apresentando a seguinte hipótese: partindo de uma lacuna da literatura, dentre os parlamentares com maior quantidade de seguidores em suas mídias sociais, os outliers, deve ser possível notar níveis positivos de associação com os deputados classificados como outsiders.

Nossa hipótese foi negada visto que, a partir dos testes estatísticos, não foi possível estabelecer uma níveis de associação estatisticamente significativos entre ser outlier nas redes e pertencer à categoria de outsider na política. Ainda, quando analisado a quantidade de parlamentares outliers por região, é possível notar que o número de outliers está mais atrelado a rede social do que a região. Assim, consideramos que para termos uma análise mais precisa da temática é necessário a realização de estudos futuros que englobem todas as regiões do país.

Apesar dos dados não confirmarem nossa hipótese, eles apresentam perguntas relevantes para futuros estudos, tais como: se entre os outliers, ser outsider não está associado ao bom rendimento nas redes, qual variável pode elucidar essa questão? Ao que parece, estudos que englobam análises 
mais qualitativas no sentido do tipo de conteúdo que é postado por esses parlamentares podem ser um possível caminho para o desenvolvimento dessa temática.

\section{REFERÊNCIAS}

BARR, Robert R. Populists, Outsiders and Anti-Establishment Politics. Party Politics, v. 15, n. 1, 2009.

BECKER, Howard Saul. Outsiders: Estudos de sociologia do desvio.1.ed. Rio de Janeiro: ZAHAR, 2008.

BRAGA, Sérgio Soares. O Uso das Mídias Sociais é Um Bom Preditor do Sucesso Eleitoral dos Candidatos? Uma análise das campanhas on-line dos vereadores das capitais das regiões sul, sudeste, e nordeste do Brasil no pleito de outubro de 2012. Revista Política Hoje - ISSN: 0104-7094, v. 22, n. 2, p. 125-148, 2013.

CARRERAS, Miguel. Outsiders and executive-legislative conflict in Latin America (1980-2007). Latin American Politics and Society, v. 56, n.3, 2014.

CORRALES, Javier. Latin America's Neocaudillismo: ex-presidents and newcomers running for President... and winning. Latin American Politics and Society, v. 50, n. 3, 2008.

CRUZ, Letícia Carina. ELITES PARLAMENTARES E NTICs: UM ESTUDO SOBRE O USO DA INTERNET PELOS DEPUTADOS ESTADUAIS BRASILEIROS DA $16^{\text {a }}$ LEGISLATURA (2007-2011). Curitiba. Dissertação (Mestrado em Ciência Política).Universidade Federal do Paraná, 2011.

CERVI, Emerson U. Manual de métodos quantitativos para iniciantes em Ciência Política. V.1. Curitiba: CPOP-UFPR, 2017.

ELIAS, Norbert; SCOTSON, John. Os Estabelecidos e os Outsiders: Sociologia das relações de poder a partir de uma pequena comunidade. Rio de Janeiro: Jorge ZAHAR ED., 2000.

MARENCO, André. Nas fronteiras do campo político: raposas e ousiders no Congresso Nacional. Revista Brasileira de Ciências Sociais, São Paulo, v. 33, p. 87-101, 1997.

SAMPAIO, Rafael Cardoso; BRAGATTO, Rachel Callai and NICOLAS, Maria Alejandra. A construção do campo de internet e política: análise dos artigos brasileiros apresentados entre 2000 e 2014. Rev. Bras. Ciênc. Polít. [online]. 2016, n.21, pp.285-320. 